\title{
Pharmacoeconomic Evaluation on Treatment of Diabetic Patients in a Charitable Hospital
}

SOFIA SUNNY, C. S. SHASTRY*, U. V. MATETI, S. CHAND ${ }^{1}$ AND R. SHARMA ${ }^{1}$

Department of Pharmacy Practice, NGSM Institute of Pharmaceutical Sciences, ${ }^{1}$ Department of General Medicine, Justice K. S. Hegde Charitable Hospital, Nitte (Deemed to be University), Deralakatte, Mangaluru-575 018, India

Sunny et al.: Pharmacoeconomic Evaluation of Diabetic Treatment 
This study aimed to conduct a pharmacoeconomic evaluation of the treatment of diabetic patients in a charitable hospital. A retrospective study was carried out for a period of 8 months from August 2016-March 2017. Patients admitted in general medicine with age above 18 years diagnosed with diabetes and on at least one antidiabetic medication. Patient's data was collected by referring patient's treatment charts and case notes, hospital billing system, medical record department and hospital pharmacy department. In this study, the direct medical cost was analysed. A total number of 212 diabetic patients were enrolled in the study of which $131(61.8 \%)$ were males, and $81(38.2 \%)$ were females. It was found that $67 \%$ of patients had comorbid conditions and $33 \%$ without any complications. One hundred and eleven $(52.35 \%)$ patients were prescribed a combination of insulin and oral hypoglycaemic agents, $66(31.13 \%)$ patients received insulin alone and $35(16.50 \%)$ patients received only oral hypoglycaemic agents. The annual median cost incurred for the management of diabetes with and without complications per patient was INR 14959.60 and INR 8619.90, respectively. The study revealed that the costs for males with and without diabetes complications were INR 21095 and INR 11 644.70, respectively. The corresponding figure for females was INR 12030 and INR 8515. The cost incurred for nephropathy and peripheral circulatory co-morbidities was the highest (INR 53 795.50), whereas the cost for managing diabetes with nephropathy, neuropathy, retinopathy and peripheral circulatory comorbidities was INR $37 \mathbf{8 8 8 . 0 0}$. The study concluded that the cost of treatment could be drastically reduced by early identification and treatment of diabetes thereby preventing the development of diabetes-associated comorbidities.

Key words: Pharmacoeconomics, diabetes, cost analysis, drug evaluation

Diabetes mellitus (DM) is a chronic disorder with various complications that affect all age groups. The International Diabetes Federation (2017) estimates 1 in 11 adults have DM (425 million) and 1 in 2 adults with DM are undiagnosed $(212 \text { million })^{[1]}$. Twelve percent of worldwide health expenditure is on DM ( $\$ 727$ billion) and there will be 629 million people with DM in the world by 2045. In India, 72.9 million individuals are living with DM and the country is ranked second in the world, after China. The Indian total healthcare cost on diabetic patients in 2017 was \$ 31 billion $^{[2]}$. In individuals who have controlled blood glucose level, the complications such as macrovascular and microvascular are less frequent and less severe ${ }^{[3,4]}$. The cost of medication is a significant obstacle in the effective treatment of the disease and consistency towards the medication regimen. The studies on the cost of illness have established that 3 times rise in the direct costs of diabetic patients compared with nondiabetic patients ${ }^{[5]}$. In India, cost studies in diabetes were conducted in Bengaluru urban district, Chennai, Warangal and North India ${ }^{[6,7,8,9]}$. The present study was conducted in a Charitable hospital, Mangaluru, Dakshina Kannada District to evaluate the direct medical cost of diabetic patients.

A retrospective study was carried out for a period of 8 mo from August 2016-March 2017 at Justice K. S. Hegde Charitable Hospital, Dakshina Kannada, Mangaluru. This study was approved by the Institutional

*Address for correspondence

E-mail: drcshastry@gmail.com
Ethical Committee (REF: INST.EC/EC/72/2016-17). The sample size was calculated using the formula, $\mathrm{n}=\mathrm{Z}_{1-\alpha / 2}^{2}\left[2 \mathrm{~S}_{\mathrm{p}}^{2}\right] / \mathrm{d}^{2}$, where, $\mathrm{Z}=1.96, \alpha=$ level of significance $(5 \%), d=$ precision $(10 \%), S_{p}=$ standard deviation (50), $\mathrm{n}=$ number of patients. The minimum sample size required for this study is 192 patients.

The study was carried out based on following inclusion and exclusion criteria. Patients admitted in general medicine department with age above $18 \mathrm{y}$ and diagnosed with DM and treated with at least one antidiabetic medication (oral antidiabetic drugs or insulin) and with or without complications. Patients hospitalised for a minimum of $2 \mathrm{~d}$ were only included in the study. The patients being treated as outpatients, with incomplete medical records and gestational diabetes patients were excluded from the study.

The data was collected by referring patient's treatment charts and case notes, hospital billing system, medical record department (MRD) and hospital pharmacy department. Patient demographic parameters such as age, gender, social habits, family history, body mass index (BMI), complications and length of hospitalization,

This is an open access article distributed under the terms of the Creative Commons Attribution-NonCommercial-ShareAlike 3.0 License, which allows others to remix, tweak, and build upon the work non-commercially, as long as the author is credited and the new creations are licensed under the identical terms

Accepted 12 April 2020

Revised 22 January 2020

Received 04 July 2019

Indian J Pharm Sci 2020;82(3):532-537 
and laboratory tests were recorded during the treatment period. Details of drug therapy such as generic and brand name of the drug, dosage form, frequency, route of administration, and number of drugs per prescription were recorded. For pharmacoeconomic evaluation, laboratory investigation, treatment bills of the antidiabetic therapy (unit dose prescribed, frequency, and route of administration and duration of treatment), physician consultations, nursing services and hospital charges were collected. Costs in Indian Rupee (INR) were converted into the United States Dollar (USD) at the rate of $1 \mathrm{USD}=64.62 \mathrm{INR}$ (During the period of the study).

Continuous variables such as age, gender, BMI, the total number of drugs prescribed, types of antidiabetic medications prescribed were expressed as mean \pm standard deviation, and skewed variables such as length of hospital stay, duration of diabetes, the annual median cost of diabetes were expressed as a median and inter-quartile range $\left(Q_{3}-Q_{1}\right)$. The categorical variables were expressed as frequency and percentage. The data analysis was carried out using the Statistical Package for Social Science (SPSS) 20.0 version.

Two hundred and twelve diabetes patients were included in this study. Out of these patients, 145 (68.4\%) patients have been diagnosed with type $2 \mathrm{DM}$ and $67(31.6 \%)$ patients with type $1 \mathrm{DM}$. In this study, $131(61.8 \%)$ male patients outnumbered the females $81(38.2 \%)$. The mean age and BMI of the study population was $55.59 \pm 14.61 \mathrm{y}$ and $23.97 \pm 2.38 \mathrm{~kg} / \mathrm{m}^{2}$, respectively. The median length of hospital stay was 10 (6-20) d. The mean number of drugs prescribed for patients was $12.88 \pm 6.56$. Ninety eight (46.2\%) patients were non-alcoholics and non-smokers, followed by both alcoholic and smoker 57 (26.9\%), only smoker $31(14.6 \%)$ and only alcoholic $26(12.3 \%)$. One hundred forty three $(67.4 \%)$ patients had no family history of diabetes and the remaining 69 (32.6\%) had family history either maternal, paternal or both. It was found that $142(67 \%)$ of diabetic patients were presented with complications and 70 (33\%) without complications. $37.7 \%$ of patients had peripheral circulatory (hypertension and diabetic foot ulcer) complications, $14.3 \%$ had ophthalmic complications and $13 \%$ of patients had neurological complications. The detailed results of age wise distribution, domiciliary status, annual hospitalstay,lengthofhospitalstay,numberofmedications prescribed and complications are summarized in Table 1.
The data showed that $111 \quad(52.35 \%)$ patients were prescribed a combination of insulin and oral hypoglycaemic agents (OHA) followed by insulin alone $66(31.13 \%)$ and OHAs $35(16.50 \%)$. It was found that biguanides $(47.6 \%)$ were the mostly prescribed class of oral antidiabetic drug followed by sulphonylureas $(25.2 \%)$ and other classes of oral hypoglycaemic agents. The complete data are summarized in Table 2 . The most commonly prescribed OHAs were, metformin 68 (47.5\%), voglibose 27 (18.9\%), glimepiride

TABLE 1: DEMOGRAPHIC CHARACTERISTICS OF THE PATIENTS

\begin{tabular}{|c|c|}
\hline Demographic characteristics & $\begin{array}{l}\text { Number of } \\
\text { patients (\%) } \\
(n=212)\end{array}$ \\
\hline \multicolumn{2}{|l|}{ Age group (y) } \\
\hline $18-39$ & 27 (12.73\%) \\
\hline $40-59$ & $90(42.45 \%)$ \\
\hline$\geq 60$ & $95(44.48 \%)$ \\
\hline \multicolumn{2}{|l|}{ Domiciliary status } \\
\hline Rural & $96(45 \%)$ \\
\hline Urban & $116(55 \%)$ \\
\hline \multicolumn{2}{|l|}{ Duration of diabetic history $(y)$} \\
\hline$<1$ & $36(16.98 \%)$ \\
\hline $1-5$ & $51(24.05 \%)$ \\
\hline $6-10$ & $61(28.77 \%)$ \\
\hline$\geq 11$ & $64(30.18 \%)$ \\
\hline \multicolumn{2}{|l|}{ Number of annul hospitalizations } \\
\hline 1 & $151(71.22 \%)$ \\
\hline 2 & $37(17.45 \%)$ \\
\hline 3 & $15(7.07 \%)$ \\
\hline 4 & $9(4.24 \%)$ \\
\hline \multicolumn{2}{|l|}{ Length of annual hospital stay (d) } \\
\hline $1-15$ & $141(66.50 \%)$ \\
\hline $16-30$ & $40(18.86 \%)$ \\
\hline $31-45$ & $19(8.96 \%)$ \\
\hline $46-60$ & $8(3.77 \%)$ \\
\hline$>60$ & $4(1.88 \%)$ \\
\hline \multicolumn{2}{|l|}{$\begin{array}{l}\text { Complications of DM } \\
\text { Retinopathy+nephropathy }\end{array}$} \\
\hline Retinopathy+neuropathy & $4(1.88 \%)$ \\
\hline Retinopathy+neuropathy & $5(2.35 \%)$ \\
\hline +peripheral circulatory & $8(3.77 \%)$ \\
\hline Nephropathy+peripheral circulatory & $3(1.41)$ \\
\hline Neuropathy+peripheral circulatory & $6(2.83 \%)$ \\
\hline Retinopathy+peripheral circulatory & $7(3.33 \%)$ \\
\hline $\begin{array}{l}\text { Nephropathy+neuropathy } \\
\text { +retinopathy+peripheral circulatory }\end{array}$ & $15(7.07 \%)$ \\
\hline Nephropathy+retinopathy & $11(5.18 \%)$ \\
\hline +peripheral circulatory & $80(37.73)$ \\
\hline Peripheral circulatory & $28(13.20)$ \\
\hline Neuropathy & $30(14.15)$ \\
\hline Ophthalmic & $15(7.54 \%)$ \\
\hline \multicolumn{2}{|l|}{ Nephropathy } \\
\hline Number of medication per prescription & 92 (43.39\%) \\
\hline $1-10$ & $88(41.50 \%)$ \\
\hline $11-20$ & $32(15.09 \%)$ \\
\hline $\begin{array}{l}21-30 \\
>31\end{array}$ & $1(0.47 \%)$ \\
\hline
\end{tabular}


21 (14.6\%), gliclazide, glibenclamide, repaglinide 6 (4.1\%), pioglitazone 5 (3.4\%), glipizide $3(2 \%)$ and sitagliptin $1(0.69 \%)$, respectively.

The annual median cost incurred for the management of DM with and without complications per patient was INR 14959.60 and INR 8619.90, respectively. The detailed cost categories of the DM patients with and without complications are summarized in Tables 3 and 4 . The study results revealed that the costs for male patients with and without complications (21 095 INR and 11644.70 INR) were more than female (12 030 INR and 8515 INR). The annual cost incurred in the presence of nephropathy and peripheral circulatory was $53795.50 \mathrm{INR}$, which was the highest followed by patients with nephropathy, neuropathy, retinopathy and peripheral circulatory conditions

TABLE 2: PRESCRIBING PATTERN OF DIFFERENT CLASSES OF ORAL HYPOGLYCAEMIC AGENTS

\begin{tabular}{lc}
\hline $\begin{array}{l}\text { Class of oral hypoglycaemic } \\
\text { agents }\end{array}$ & $\begin{array}{c}\text { Number of patients } \\
(\%)(n=212)\end{array}$ \\
\hline Sulphonylureas & $36(25.2 \%)$ \\
Biguanides & $68(47.6 \%)$ \\
Meglitinides & $6(4.2 \%)$ \\
Thiazolidinediones & $5(3.5 \%)$ \\
Dipeptidyl peptidase-4 inhibitors & $1(0.7 \%)$ \\
a-glucosidase inhibitors & $27(18.8 \%)$ \\
\hline
\end{tabular}

(37 888 INR) and others complications are summarized in Table 5.

The rise in the incidence of diabetes produces clinical, financial and social burden. The cost of diabetic care is increasing globally ${ }^{[10]}$. The present study was intended to analyse the medical cost involved in the management of diabetic patients with or without complications. Cost analysis of a total of 212 diabetic patients was performed during the study period. Out of 212 patients, most of the patients were male $(61.8 \%)$. Among them, the maximum number of patients was in the age 60 or above $(44.48 \%)$. These findings are consistent with studies reported by Akari et al., Al-Maskari et al., and Raj et al. ${ }^{[9,13,14]}$

In the present study, majority of the DM patients admitted only once $(71.25 \%)$ in the annual hospitalization report, this might be due to proper prescription of drugs, patient counselling and adherence to the treatment regimen. Contradictory results were reported by Assefa et al. that diabetic patients had 3-6 (52.31\%) hospitalizations per annum $^{[15]}$.

Sixty nine (32.6\%) patients under study had no family history, which is significantly less that reported by Akari et al., who showed $58 \%$ patients had a positive family history of diabetes ${ }^{[9]}$. The mean BMI of the

TABLE 3: ANNUAL COST PER DIABETIC PATIENT WITH COMPLICATIONS

\begin{tabular}{lcc}
\hline \multirow{2}{*}{ cost category } & Cost of DM patients with complications & Cost of DM patients with complications \\
\cline { 2 - 3 } & Median $\left(\mathbf{Q}_{3}-\mathbf{Q}_{1}\right)$ in INR & Median $\left(\mathbf{Q}_{3}-\mathbf{Q}_{1}\right)$ in USD \\
\hline Anti-diabetic medications & $517(1332.60-298.40)$ & $13.86(20.62-4.62)$ \\
Medications for complications & $1889(3991-213)$ & $29.23(61.76-3.30)$ \\
Other medications & $697.30(1690.50-296)$ & $10.79(26.16-4.58)$ \\
Laboratory tests & $2225.70(5225-773.70)$ & $34.44(80.85-3.56)$ \\
Consultation & $2078.80(4387.50-230)$ & $32.17(67.89-3.56)$ \\
Nursing services & $549.40(1352.50-253.70)$ & $8.50(20.93-3.93)$ \\
Hospitalization & $2027.50(3640-1515)$ & $31.38(56.33-23.44)$ \\
Miscellaneous & $1384.40(3362.50-593.70)$ & $21.42(52.03-9.19)$ \\
TOTAL & $14959.60(36168-6549)$ & $231.50(559.70-101.35)$ \\
\hline
\end{tabular}

INR- Indian Rupees, USD- United State Dollars

TABLE 4: ANNUAL COST PER DIABETIC PATIENT WITHOUT COMPLICATIONS

\begin{tabular}{lcc}
\hline \multirow{2}{*}{$\begin{array}{l}\text { Cost category } \\
\text { Antidiabetic medications }\end{array}$} & $\begin{array}{c}\text { Cost of DM patients without } \\
\text { complications }\end{array}$ & $\begin{array}{c}\text { Cost of DM patients without } \\
\text { complications }\end{array}$ \\
\cline { 2 - 3 } Other medications & Median $\left(\mathbf{Q}_{3}-\mathbf{Q}_{1}\right)$ in INR & $6.47(16.40-3.47)$ \\
Laboratory tests & $417.90(1060-224.20)$ & $5.92(14.41-2.56)$ \\
Consultation & $382.90(931.40-165.60)$ & $14.46(32.94-8.67)$ \\
Nursing services & $934.50(2128.70-560)$ & $13.91(33.93-3.95)$ \\
Hospitalization & $899(2192.50-255)$ & $4.58(13.26-4.10)$ \\
Miscellaneous & $296.30(857.50-265)$ & $8.90(14.08-4.02)$ \\
TOTAL & $575(910-260)$ & $11.06(22.28-6.34)$ \\
\hline
\end{tabular}

INR- Indian Rupees, USD- United State Dollars 
TABLE 5: ANNUAL COST OF COMPLICATIONS

\begin{tabular}{lcc}
\hline Type of complication & $\begin{array}{c}\text { Cost of patients with } \\
\text { complications } \\
\text { Median }\left(\mathbf{Q}_{3}-\mathbf{Q}_{1}\right) \text { in INR }\end{array}$ & $\begin{array}{c}\text { Cost of patients with } \\
\text { complications } \\
\text { Median }\left(\mathbf{Q}_{3}-\mathbf{Q}_{1}\right) \text { in } \text { USD }^{-}\end{array}$ \\
\hline Nephropathy & $9481(26818-6913)$ & $146.71(415.01-106.97)$ \\
Retinopathy & $12171.50(30546.00-6226.50)$ & $188.35(472.7-96.35)$ \\
Neuropathy & $7759(21816-4482.70)$ & $120.07(337.6-69.37)$ \\
Peripheral circulatory & $15469.50(33101-8561)$ & $239.39(512.24-132.48)$ \\
Retinopathy+nephropathy+peripheral circulatory & $15131(20577.20-5709.20)$ & $234.15(318.43-88.35)$ \\
Retinopathy+peripheral circulatory & $14583(54586.00-8925.50)$ & $225.67(844.72-138.12)$ \\
Nephropathy+neuropathy+retinopathy+peripheral & $37888(62593-11657)$ & $586.32(968.63-180.39)$ \\
circulatory & & $133.13(424.50-74.21)$ \\
Neuropathy+peripheral circulatory & $8603(27431.20-4795.70)$ & $832.48(1248.91-416.06)$ \\
Nephropathy+peripheral circulatory & $53795.50(80705-26886)$ & $345.54(654.77-109.60)$ \\
Retinopathy+neuropathy+peripheral circulatory & $22329(42311.20-7082.50)$ & $60.03(122.88-44.19)$ \\
Retinopathy+neuropathy & $3879.50(7940.70-2855.70)$ & $456.40(486.55-117.36)$ \\
Retinopathy+nephropathy & $29493(31441-7584)$ & \\
\hline
\end{tabular}

INR- Indian Rupees, USD- United State Dollars

study population was $23.97 \pm 2.38 \mathrm{~kg} / \mathrm{m}^{2}$, whereas other studies by Acharya et al., Akari et al., and Al-Maskari et al. reported BMI values higher than $25 \mathrm{~kg} / \mathrm{m}^{2[5,9,13]}$.

It was observed that $67 \%$ of patients had co-morbidities and $33 \%$ were without co-morbidities, these findings were consistence with the reported by Rayappa et al., which also had maximum patients with co-morbid conditions ${ }^{[17]}$. In this study, majority of the patients had peripheral circulatory complications (37.7\%), which included hypertension and diabetic foot ulcers followed by ophthalmic complications (14.3\%). A similar study conducted by Acharya et al., reported that maximum patients had microvascular complications ${ }^{[5]}$. In the present study, complications were categorized individually rather than classifying it as microvascular and macrovascular.

Regarding the class of drugs used for the management of diabetes, $52.35 \%$ of patients were prescribed with a combination of insulin and OHAs followed by insulin alone $(31.13 \%)$ and OHAs $(16.50 \%)$. Contradictory results were reported by Acharya et al., that the majority of patients were on OHAs followed by insulin ${ }^{[5]}$. Among the different class of OHAs prescribed, it was found that biguanides were mostly prescribed $47.6 \%$ followed by sulphonylureas $25.2 \%$. These findings are similar to the study conducted by Alex et al. ${ }^{[12]}$.

The overall annual hospitalization cost of diabetes with complications was found to be higher than diabetes without complications. Similar results were reported by Acharya et al. in which the hospitalization cost was 1.2 times higher for diabetic patients with complications $^{[5]}$. The annual median medication cost of diabetes with complications was found to be
2.5 times higher than diabetes without complications. These findings are similar to those reported by Acharya et al., who reported a 1.7 times higher cost for diabetes with complications than diabetes without complications $^{[5]}$. The study conducted by Kapur et al. reported that diabetic complications were responsible for most of the diabetes-related direct health costs in India $^{[7]}$. The overall median annual cost of diabetes with complications was found to be higher in male patients (\$ 326.40) than female patients (\$ 186.16). These results are comparable to the study of Akari et al. ${ }^{[9]}$ for diabetes with and without complications.

In the present study, the annual cost incurred for diabetes with nephropathy and peripheral circulatory complications ( $\$ 832.48$ ) was the highest followed by for diabetes with nephropathy, neuropathy, retinopathy and peripheral circulatory complications (\$ 586.32), followed by others complications. A similar study conducted by Akari S et al., revealed that the cost for macrovascular complications (\$ 129) was more than that for microvascular complications $(\$ 84.64)^{[9]}$. Previous study results also showed that the costs of macrovascular complications were higher than the microvascular complications ${ }^{[13,18,19]}$.

The total annual cost of treatment in patients with complications (14 959.60 INR) was higher compared to without complications (8619.90 INR). The yearly cost incurred for the treatment of people with diabetes with nephropathy and peripheral circulatory complications (53 795.50 INR) was highest followed by diabetes with nephropathy, neuropathy, retinopathy and peripheral circulatory complications (37 888 INR) and other diabetic complications, respectively. Poorly managed diabetes increases the financial burden on the family 
and society. The outcomes of the study reveal the need for early identification and prevention of diabetic complications to control the cost of diabetes.

\section{Acknowledgements:}

The authors thank Justice K. S. Hegde charitable hospital for granting permission to carry out the research work. We also thank the MRD for providing necessary and timely data to carry out the research work. We sincerely thank Professor Krishna Bhat for his continuous guidance during research work for statistical analysis.

\section{Conflict of interest:}

None

\section{Financial support and sponsorship:}

Nil.

\section{REFERENCES}

1. International Diabetes Federation (2017) - Key messages. [cited May 1, 2018]. Available from: http://www.diabetesatlas. org/key-messages.html.

2. International Diabetes Federation (IDF) Diabetes Atlas - 8th ed. 2017. [cited May 1, 2018]. Available from: http://www. diabetesatlas.org/resources/2017-atlas.html.

3. Gaede P, Lund-Andersen H, Parving HH, Pedersen O. Effect of a multifactorial intervention on mortality in type 2 diabetes. N Engl J Med 2008;358:580-91.

4. Rayappa PH, Raju KNM, Kapur A. Economic cost of diabetes care: The Bangalore Urban District Diabetes Study. Int J Diab Dev Countries 1999;19:87-97.

5. Acharya LD, Rau NR, Udupa N, Rajan MS, Vijayanarayana $\mathrm{K}$. Assessment of cost of illness for diabetic patients in South Indian tertiary care hospital. J Pharm Bioall Sci 2016;8:31420.

6. Shobhana R, Rama Rao P, Lavanya A, Williams R, Vijay V, Ramachandran A. Expenditure on health care incurred by diabetic subjects in a developing country - A study from Southern India. Diabetes Res Clin Pract 2000;48:37-42.
7. Kapur A, Bjork S, Nair J, Kelkar S, Ramachandran A. Socioeconomic determinants of the cost of diabetes in India. Diabetes Voice 2004;49:18-21.

8. Grover S, Avasthi A, Bhansali A, Chakrabarti S, Kulhara P. Cost of ambulatory care of diabetes mellitus: A study from North India. Postgrad Med J 2005;81:391-5.

9. Akari S, Mateti UV, Kunduru BR. Health-care cost of diabetes in South India: A cost of illness study. J Res Pharm Pract 2013;2:114-7.

10. Ramachandran A. Socio-economic burden of diabetes in India. J Assoc Physicians India 2007;55 Suppl:9-12.

11. Abidi A, Rizvi DA, Ahmad A. Pharmacoeconomic and Drug Utilization Study of Antidiabetic Therapy in a Tertiary care Teaching Hospital of Northern India. Asian J Pharm Clin Res 2016;9:371-75.

12. Alex SM, Sreelekshmi BS, Smitha S, Jiji KN, Menon AS, Uma DP. Drug Utilization Pattern of Antidiabetic drugs Among Diabetic Outpatients in a Tertiary Care Hospital. Asian J Pharm Clin Res 2015;8:144-6.

13. Al-Maskari F, El-Sadig M, Nagelkerke N. Assessment of the direct medical costs of diabetes mellitus and its complications in the United Arab Emirates. BMC Public Health 2010;10:679.

14. Raj K, Kamlesh K, Kajal HL. A Study of Drug Prescribing Pattern and Cost Analysis among Diabetic Patients in a Tertiary care Teaching Institute in Northern India. J Drug Deliv Ther 2013;3:56-61.

15. Assefa B, Wondimu A, Abrha S, Dinda SC, Demeke B, Samuel NG et al. Pharmacoeconomic Evaluation of Anti Diabetic Treatment at Ayder Referral Hospital, Mekelle, Ethiopia. Int J Pharm Sci Res 2014;25:47-52.

16. Acharya KG, Shah KN, Solanki ND, Rana DA. Evaluation of antidiabetic prescriptions, cost and adherence to treatment guidelines: A prospective, cross- sectional study at a tertiary care teaching hospital. J Basic Clin Pharm 2013;4:82-7.

17. Rayappa PH, Raju KNM, Kapur A, Bjork S, Sylvist C, Kumar KMD. The Impact of Socio-Economic Factors on Diabetes Care. Int J Diab Dev Countries 1999;19:87-96.

18. Tharkar S, Devarajan A, Kumpatla S, Viswanathan V. The socioeconomics of diabetes from a developing country: A population based cost of illness study. Diabetes Res Clin Pract 2010;89:334-40.

19. Bahia LR, Araujo DV, Schaan BD, Dib SA, Negrato CA, Leão MP, et al. The costs of type 2 diabetes mellitus outpatient care in the Brazilian public health system. Value Health 2011;14:S137-40. 